\title{
Technology Solutions for Collaborative Product Lifecycle Management - Status Review and Future Trend
}

\author{
X. G. Ming, ${ }^{1, *}$ J. Q. Yan, ${ }^{1}$ W. F. $\mathrm{Lu}^{2}$ and D. Z. Ma ${ }^{1}$ \\ ${ }^{1}$ School of Mechanical and Power Engineering, Shanghai Jiao Tong University, No. 1954 Huashan Road \\ Shanghai, 200030, PR China \\ ${ }^{2}$ Design Technology Institute, Department of Mechanical Engineering, National University of Singapore \\ 9 Engineering Drive 1, 117576, Republic of Singapore
}

\begin{abstract}
In the modern global economy, companies are facing ever-increasing challenges for short time-to-market to enter into the market early, for reduced time-to-volume to occupy the market quickly, and for decreased time-to-profit to get return from market shortly. Product lifecycle management (PLM) is recognized as one of the key leading technologies to facilitate companies to overcome these challenges, which will offer companies a new way to rapidly plan, organize, manage, measure, and deliver new products or services much faster, better, and cheaper in an integrated way. Following this trend, this study proposes a full scenario of technology solutions for PLM based on the complete analysis of business drivers, industry requirements, limit of current solution, and recent state-of-the-art review in the domain related to PLM. Potential industrial impact of the developed PLM technology solutions is analyzed. It is hoped that the proposed PLM technology solutions will form the frontier basis for further research, development, and application of PLM systems to quickly adapt to the dynamic changing market for industry companies to pursue the most advanced competitiveness.
\end{abstract}

Key Words: product lifecycle management, collaborative product service, product lifecycle process management, product lifecycle knowledge management, product data management.

\section{Introduction}

In today's highly competitive environment, business requirements always drive technology solutions. In response to increasing customer demand and dynamic competition, companies are under high pressure to shorten time-to-market by providing tailored products to the customer for the economy of scope, to reduce time-to-volume via mass production for the economy of scale, and to decrease time-to-profit by increasing the efficiency of the entire lifecycle for the economy of service. These business requirements drive technology needs

1. to speed up product development,

2. to enhance manufacturing and supply capability and capacity, and

3. to improve revenue from lifecycle efficiency.

To tackle such challenges, in past decades, with the support of advanced manufacturing technologies, manufacturing industry has shifted from

*Author to whom correspondence should be addressed

E-mail: xgming@sjtu.edu.cn

Figures 1 and 2 appear in color online: http://cer.sagepub.com mass production, which takes the advantage of scale of production, to concurrent engineering, which optimizes internal enterprise processes, and virtual enterprise, which leverages intellectual capital via collaborative innovation [1]. In such a virtual enterprise environment, companies need to closely collaborate with customers, manufacturers, and suppliers in a real time manner so as to quickly respond to dynamic market changes.

Accordingly, the business model in the manufacturing industry has shifted from make-to-order, to build-toorder, to engineering-to-order, to configure-to-order, to design-to-order, and in near future to innovate-toorder. Key technologies to support these business models have changed as well from mass production, to a flexible manufacturing system, to manufacturing knowledge management, to product customization, to product knowledge management, and to product lifecycle management (PLM). As such, PLM is recognized by world's leading universities, institutes, and solution vendors as the next big wave in enterprise application software market.

Product lifecycle includes the processes of portfolio management, product design, process design, supply, production, launch, service, and recycle. Throughout the entire product lifecycle, there exist three major objectives, which are customer benefit such as product 
quality and serviceability, company benefit such as product cost and profit, and society benefit such as clean and green environment. These benefits become the 'WHY' aspect of product lifecycle. Bearing these benefits in mind, the 'WHAT' aspect of product lifecycle can be created, which is to model product specification, function, behavior, structure, geometry, topology, machining process, schedule, supply chain, operation service, recycling, and disposal. The next step is 'HOW' to model the product lifecycle, which are lifecycle processes including specification management, conceptual design, detailed design, process design, production, supply, service, and recycle.

1. To reach customer benefits, mass customization, time-to-innovation, product quality, and reliability are recognized as the key approaches enabled with technologies, e.g., product family design, platformbased design, modular product design, design process modeling and management, design knowledge management, collaborative design engineering, function/behavior/structure design, etc.

2. To achieve company benefits, time-to-market, timeto-volume, and time-to-profit are known as the key approaches enabled with technologies, e.g., collaborative product service, product lifecycle process management, product lifecycle information and knowledge management, etc.

3. To obtain society benefits, design for service, design for reuse, design for recycle are justified as the key approaches enabled with technologies, e.g. product/ service co-design, collaborative early design for lifecycle efficiency, environmentally conscious design, etc.

This article will focus on the discussion of technology solutions to achieve company benefits in product lifecycle, namely, product lifecycle management (PLM), which is also the dominant direction in the current market of enterprise software application. PLM provides customers, developers, manufacturers, and suppliers with the most effective means by collaboratively managing business activities throughout entire product lifecycle. PLM supports the capability of collaborative creation, management, dissemination, and use of product assets (including data, information, and knowledge) in virtual enterprise integrating people, processes, and technology. PLM systems manage a portfolio of products, processes, and services from initial concept, through design, engineering, to final disposal. As such, PLM offers companies a new way to rapidly plan, organize, manage, measure, and deliver new products or services much faster, better, and cheaper in an integrated way. It is estimated by CIMdata that in next five years, the average growth of PLM for none Computer Aided Design and Computer
Aided Manufacturing (CAD/CAM) products and services will increase up to $17 \%$ [2].

Following this trend, in this article, ever-increasing business drivers and industrial requirements are analyzed. Corresponding solution systems required are summarized and the limit of current solutions are highlighted in Section 2. As a result, PLM is proposed as a new weapon to satisfy modern needs for new business model of innovation-to-order. A recent stateof-the-art review for PLM, including both academe and industry, is depicted and corresponding gap is analyzed in Section 3. The detailed processes throughout the entire product lifecycle are outlined in Section 4. To effectively manage these product lifecycle processes for competitive advantages via efficient collaboration, technology solutions for PLM are proposed as the future trend in Section 5. Accordingly, the impacts of PLM technology solutions to industry are analyzed in Section 6. The article ends with a conclusion. It is hoped that this article will probably form the frontier basis for research community to conduct further technology development in PLM with potential applications to satisfy industrial requirements.

\section{Challenges in Product Lifecycle}

\subsection{Business Driver}

The current business environment faces new business challenges for effective management of whole product lifecycle, e.g., shorter product lifecycles, increased outsourcing, mass customization demands, more complex products, geographically dispersed design teams, inventories subject to rapid depreciation, and rapid fulfillment needs. In general, these challenges include increased speed, increased demand; increased outsourcing, and the ubiquitous Internet.

\subsection{Industrial Requirement}

To effectively tackle the above challenges in a modern collaborative enterprise environment, new industrial capabilities are required in order to obtain business success in today's Internet economy:

1. Geographically scattered design teams and supply chain partners need to collaboratively design products on a virtual basis.

2. Static designs need to be replaced by mass customization - often using predefined modules or building blocks to rapidly configure new product platforms that can be flexibly managed through their lifecycle.

3. A new approach needs to be created to leverage netcentric technology to liberate the inherent value in today's extended business model. 
4. Such a new approach should enable business to use and leverage information needed by each partner to accelerate and enhance product development predictability.

5. To exchange and control product information and to perform real-time program/project management.

6. A system needs to emerge as the dominant technology for managing inter-enterprise data, information, and knowledge, and providing design teams with a virtual design space.

To meet these requirements, a new system is imperatively required:

1. to provide an information continuum in order to deliver pervasive, real-time analytics, querying, and reporting throughout the entire product lifecycle,

2. to provide a collaborative environment bringing together multiple roles, constituents, and stakeholders in threaded discussions beyond four walls of enterprise,

3. to enable interactive viewing and commentary upon product development through multiple devices, channels, and systems involved with the product lifecycle,

4. to be an open but integrated solution supporting key enterprise value disciplines of product leadership, customer intimacy, and operational excellence.

Such a new system will provide customers, developers, manufacturers, suppliers, and partners with the following capabilities:

1. product lifecycle collaboration across virtual enterprises

2. common product lifecycle processes management

3. effective management of product lifecycle activities

4. convenient integration with other enterprise systems

\subsection{Limit of Current Solution}

To tackle continuously emerging new business challenges, in the past several decades, both academic and industrial researchers have put in tremendous efforts in research and development of industrial information technologies to pursue the most competitive business advantages. However, current product design and development in most companies still encounter a lot of difficulties, such as:

- Shifting design from a departmental and sequential process to a cross-company and concurrent activity has been discussed for several years.

- Using traditional product data management systems and exchanging engineering data with suppliers has proved difficult, slow, and geographically limited.
- Flawed coordination among teams, systems, and data incompatibility, and complex approval processes are common.

- Too often, the result is late product introductions, distraction of high-value staff, quality problems, or supply chain complications.

\section{State-of-the-Art Review}

\subsection{PLM Concept}

As companies move towards providing better customer-centric products and services quickly to maximally satisfy customer requirements, to improve market share and market size with continuously growing revenue, the efficiency and effectiveness of product lifecycle management becomes much more important in modern enterprise application systems. To address these needs, PLM has recently been recognized as a new strategic business approach in support of collaborative creation, management, dissemination, and use of product assets, including data, information, knowledge, etc., across extended enterprise from concept to end of life - integrating people, processes, and technology. PLM systems support the management of a portfolio of products, processes, and services from the initial concept, through the design, engineering, launch, production, and use to final disposal. They coordinate and collaborate products and project and process information throughout the product value chain among various players, internal and external to enterprise. They also support a product-centric business solution that unifies product lifecycle by enabling online sharing of product knowledge and business applications [2-4].

As such, PLM enables manufacturing organizations to obtain the greatest competitive advantages by creating better products in less time, at a lower cost, and with fewer defects than ever before. In summary, PLM not only provides service throughout the entire product lifecycle, but also enables effective collaboration among networked participants in product value chain, which differentiates it from traditional enterprise application systems, such as Enterprise Resource Planning (ERP), Manufacturing Execution System (MES), etc.

\subsection{Status Survey}

This is because, traditional application systems, e.g., computer aided design (CAD)/computer aided manufacturing (CAM) [5], computer aided process planning (CAPP) [6], helped to make the design process more efficient, but they were usually separate from a 
Table 1. Recent academic status in PLM.

\begin{tabular}{|c|c|}
\hline $\begin{array}{l}\text { Leading universities } \\
\text { and research institute }\end{array}$ & Research topics \& directions \\
\hline $\begin{array}{l}\text { University of Tokyo: } \\
\text { Product Life Cycle } \\
\text { Modeling Group }\end{array}$ & $\begin{array}{l}\text { Life Cycle Engineering, Life Cycle Design based on Simulation, Life Cycle Planning, Evaluation of Product } \\
\text { Function \& Quality, Modular Design \& Design for Upgradability, Modeling of Maintenance, Tolerance } \\
\text { Modeling for Part Reuse. Life Cycle Optimization, Reuse \& Rapid Life Cycle, Eco-Design, Service Quality }\end{array}$ \\
\hline $\begin{array}{l}\text { Stanford University: Center } \\
\text { for Design Research }\end{array}$ & Mechanical Product Design \& Development \\
\hline $\begin{array}{l}\text { MIT: Center for Innovation } \\
\text { for Product Development }\end{array}$ & $\begin{array}{l}\text { Platform Architecture, Distributed Object-based Modeling Environment, Information Flow Modeling, } \\
\text { Product Development Integration }\end{array}$ \\
\hline UC Berkeley & CyberCut: Web-based CAD/CAPP/CAM system \\
\hline $\begin{array}{l}\text { Georgia Tech: Systems } \\
\text { Realization Lab }\end{array}$ & Engineering Product, Product Family Design \\
\hline $\begin{array}{l}\text { Cambridge University: } \\
\text { Engineering Design Center }\end{array}$ & Design process and design knowledge management \\
\hline $\begin{array}{l}\text { Lancaster University: } \\
\text { Engineering Design Center }\end{array}$ & Computer aided concept design \\
\hline NIST/USA & $\begin{array}{l}\text { FIPER: Streamline the design of highly engineered products, integrating legacy and best-of-breed design } \\
\text { and analysis tools through a web-enabled environment }\end{array}$ \\
\hline Fraunhofer/Germany & $\begin{array}{l}\text { iViP: Integrated Virtual Product Creation-Under a uniform and user-friendly user interface, new tools for } \\
\text { product conception, product design, product validation, product data management, and } \\
\text { production planning }\end{array}$ \\
\hline
\end{tabular}

manufacturing company's mainstream operations. Design engineers and possibly manufacturing engineers could access these systems, but others, who may have been able to add value to the design had no systematic process by which to influence or even comment on product design. By the time these other participants provided their input, changes were either very costly to implement or were not made at all, resulting in high costs or - even worse - an inefficient product design that did not meet customer needs. Even though the modern manufacturing application systems, such as, product data management (PDM), supply chain management (SCM), enterprise resource management (ERP), manufacturing execution system (MES), customer relationship management (CRM), demand chain management (DCM), and so on, have been developed to overcome certain aspects of the above difficulties, they still cannot adequately address the need for collaborative capabilities throughout the product lifecycle because they focus on special activities in an enterprise and are not adequately designed to meet new business requirements [7-9].

A recent academic state-of-the-art review or the research effort related to PLM is summarized in Table 1. The academic pioneer in product lifecycle research is the product lifecycle modeling group at the University of Tokyo [10], focusing on the topics of lifecycle engineering, lifecycle design based on simulation, lifecycle planning, lifecycle optimization, reuse and rapid lifecycle, eco-design, service-quality, etc. The other effort includes center for design research at Stanford University [11], center for innovation for product development at Massachusetts Institute of Technology [12], web based design, process planning and manufacturing system at University of California at Berkeley [13], systems realization laboratory at Georgia Institute of Technology [14], design process and knowledge management at engineering design center of Cambridge University, computer aided concept design at engineering design center of Lancaster University, FIPER project funded by National Institute of Standards and Technology in USA [15], iViP project funded by Fraunhofer in Germany [16]. Such research efforts focus on product design and development activities by using modern computing and Internet technologies to facilitate design collaboration and potential innovation. These reported achievements form the strong basis for further research and development in PLM. However, little effort has been documented on product lifecycle technology, as what Tokyo University reported, and the result obtained is still far from satisfactory.

Table 2 summarizes the recent industrial status of PLM solutions from world's leading vendors. UGS PLM solution provides the capability of collaboration platform, collaborative project management and so on, based on Teamcenter infrastructure [17]. PTC provides the solution extended from traditional product data management (PDM) to link with supplier and project management [18]. IBM supports extended PDM solution for both multi-national companies (MNCs), via Enovia, and small and medium-sized enterprises (SMEs), via Smarteam [19]. MatrixOne supports solutions of collaborative application, lifecycle application, and modeling studio [20]. AgileSoft [21] provides solutions of product definition, product collaboration, product sourcing, etc. These solutions from different vendors, particularly the PDM solutions, have been 
Table 2. Recent industrial status in PLM.

\begin{tabular}{lc}
\hline Leading vendors & Products, services, capabilities, and functions \\
\hline UGS PLM solution & Collaboration Platform, Collaborative Project Management, PDM (Workflow \& Lifecycle Management, \\
& Change Management, Doc Management, Product Structure Management), CAD/CAM, e-Manufacturing, e-Vis \\
PTC/Windchill & PDM (Workflow \& Lifecycle Management, Change Management, Doc Management, \\
& Product Structure Management), ProjectLink, CAD/CAM \\
IBM/Dassault system & CATIA, ENOVIA, SMARTTEAM: Planning, Implementation, Design, Engineering \& Analysis, Manufacturing, \\
MatrixOne & Corvice after sales, PDM \& Collaboration \\
& development/Mfg/sales/service management; modeling studio: data schema/business \\
AgileSoft & process/user-interface modeling \\
\hline
\end{tabular}

widely applied in manufacturing industry and have created a beneficial impact on enterprises.

\subsection{Gap Analysis}

However, to get the most competitive advantages in the modern dynamic global manufacturing era, there is still a big gap between increasing demands from industrial companies and available solutions from vendors. The gaps in PLM include:

1. $\mathrm{CAD} / \mathrm{CAPP} / \mathrm{CAM}$ integration versus collaboration product development and real time design to manufacturing collaboration;

2. Product structure and configuration management versus collaborative product family design for mass customization;

3. Design for manufacturing versus design for supply chain and lifecycle efficiency;

4. Product planning versus product portfolio management;

5. Design workflow management versus product lifecycle process management;

6. Part repository for reuse versus product lifecycle knowledge management;

7. Product and part maintenance versus extended product service.

Therefore, it is imperatively required that new technology needs to be identified and further developed to enable current commercial PLM solutions to satisfy increasing industrial requirements.

\section{Processes in Product Lifecycle}

The entire product lifecycle consists of a set of processes, which are functions or tasks to create, transform, and deliver products. Past efforts to process management were primarily driven by the desire to improve the efficiency of an enterprise and reduce costs $[22,23]$. Enterprises do not realize frequently that their functionally fragmented processes often mean that the product developer has poor experience and receives less than the expected value. Successful process management should create processes that satisfy customer's requirements, meet product developer's expectations, and support developer value proposition, provide competitive differentiation and contribute to the desired product lifecycle. In order to do that, complete processes in the whole product lifecycle should be identified, which are product market strategy, product portfolio planning, product platform planning, customer requirements, product specification, conceptual design, detailed design, design analysis, prototyping and testing, process planning, inventory management, sourcing, production, inspection, packing, distribution, operation and service, disposal, and recycle [24].

This clearly indicates that the processes throughout the entire product lifecycle are complex in nature. The difficulty in managing these processes is not only the modeling, designing, integrating, automating, monitoring, and optimizing these lifecycle processes, but also the capability to support variant levels of collaboration to improve efficiency and effectiveness throughout the entire product lifecycle. Therefore, appropriate technology solutions for PLM are imperatively required to facilitate the implementation and deployment of PLM systems to benefit industrial application.

\section{Technology Solutions for PLM}

Before developing the full scenario of technology solutions for PLM, it is helpful if past successful examples can be used as a mirror. It is reported that American Society of Mechanical Engineers (ASME) has recognized $\mathrm{CAD} / \mathrm{CAM}$ as the most excellent technology invented in last century. Thirty years ago when $\mathrm{CAD} / \mathrm{CAM}$ technologies were developed, the available information technology might only be data structure, including data entity, and relationship that links data entities. Based on this technology, researchers 
invented the most important technology for CAD/CAM and made $\mathrm{CAD} / \mathrm{CAM}$ a great success, that is, the geometry and topology, where geometry represents the data entities in CAD/CAM, and topology captures relationships among geometries.

Today, there already exist advanced information technologies, reported by AMR Research [3] as Enterprise Commerce Management, including, analytic data model, industry standard application server, integration framework, business process management, private trading exchange, collaborative work space, single portal framework, and also the system management composed of security, service delivery, process event management, application management, and so on, to support the implementation of different layers in enterprise commerce management. Similar to the geometry and topology for CAD/CAM 30 years ago, it is reasonable to derive key technology layers for PLM based on the latest information technology layers. These technology solutions are identified as, product lifecycle information modeling and management, product lifecycle knowledge management, design chain management, product lifecycle process management, product trade exchange, collaborative product service, and product lifecycle portal for the end user of stakeholder, developer, customer, manufacturer, and supplier, and also PLM applications including operation technology roadmap, business process reengineering (BPR) methodology, and so on for the implementation of PLM (Figure 1).

\section{Impact to Industry}

After the development of technology solutions for PLM, it is also important to verify the impact of these technology solutions on industries. Variant industry domains impacted by the proposed technology solutions according to the types of product lifecycle versus new product development and introduction (NPD\&I) cycle include:

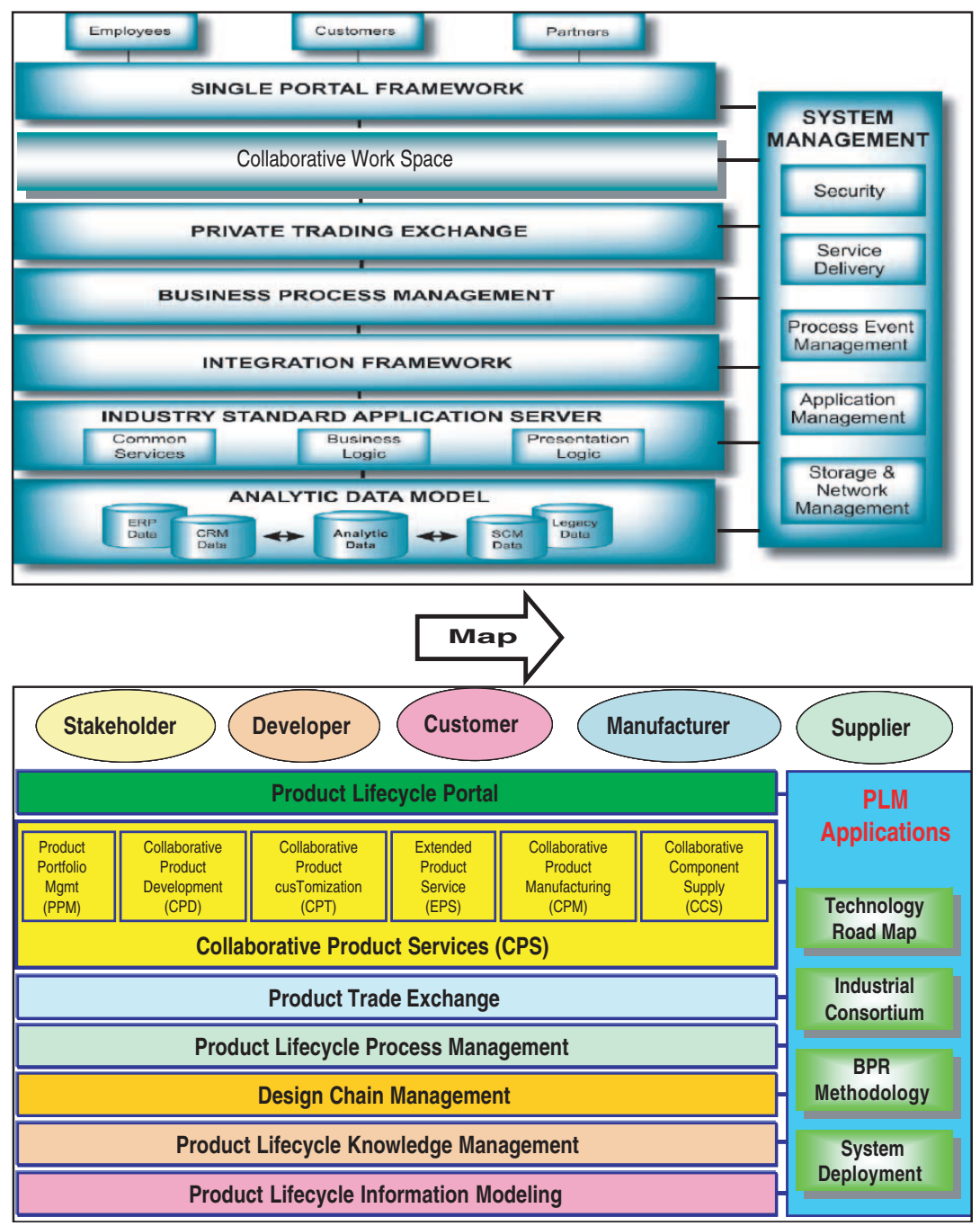

Figure 1. Mapping from information technologies to PLM technology solutions. 
1. Market driven industry, e.g., food, beverage, and consumer goods;

2. Manufacturing driven industry, e.g., consumer electronics, precision components;

3. Project driven industry, e.g., marine, aerospace, defense, pharmaceutical, equipment;

4. Technology driven industry, e.g., semiconductor, photonics, industrial information technology.

It shows that different PLM technology solutions fit into variant industry domains with different characteristics. This indicates that the technology solutions developed could have the great potential to be applied to meet industry requirements.

With the application of PLM systems in industry, potential advantages are expected as follows:

- PLM systems bring customers into the design chain, which can lead to shorter product lifecycles and higher levels of customer satisfaction.

- As nearly $70 \%$ of the product's cost is built-in during design and development phase, consequently, the best opportunity to impact costs and profit margins is during the crucial design process. PLM systems provide capability for designer, customer, manufacturer, and supplier to work closely in order to leverage intellectual capital and facilitate collaborative innovation for new and effective product design and development.

- Suppliers are experts in their respective fields and can thus add significant intellectual capital to the design process. PLM systems link designer and supplier together to get competitive advantages, such as, increased use of alternative technologies, more design reuse, better manufacturability, shorter cycle times, and lower design/production costs, etc.

\section{Conclusions}

To achieve long-term sustainability in a modern highly competitive business environment, the trend in PLM with technology solutions is proposed in this study. As shown in Figure 2, respective business issues mentioned early in this article can be effectively satisfied with technology solutions proposed. First, the Time-ToMarket issue can be addressed by product portfolio management, collaborative product development, collaborative product customization, design chain management, product lifecycle knowledge management. Second, collaborative product manufacturing and collaborative component supply address the timeto-volume issue. Third, product lifecycle process management, extended product services address the time-to-profit issue.

Indeed, the development of PLM technology solutions will lay a strong frontier basis for further development and application of PLM systems for the benefit of industries. It is hoped that the study in this article will also provide a referring guide for professional researchers to conduct further study in the PLM domain in near future.

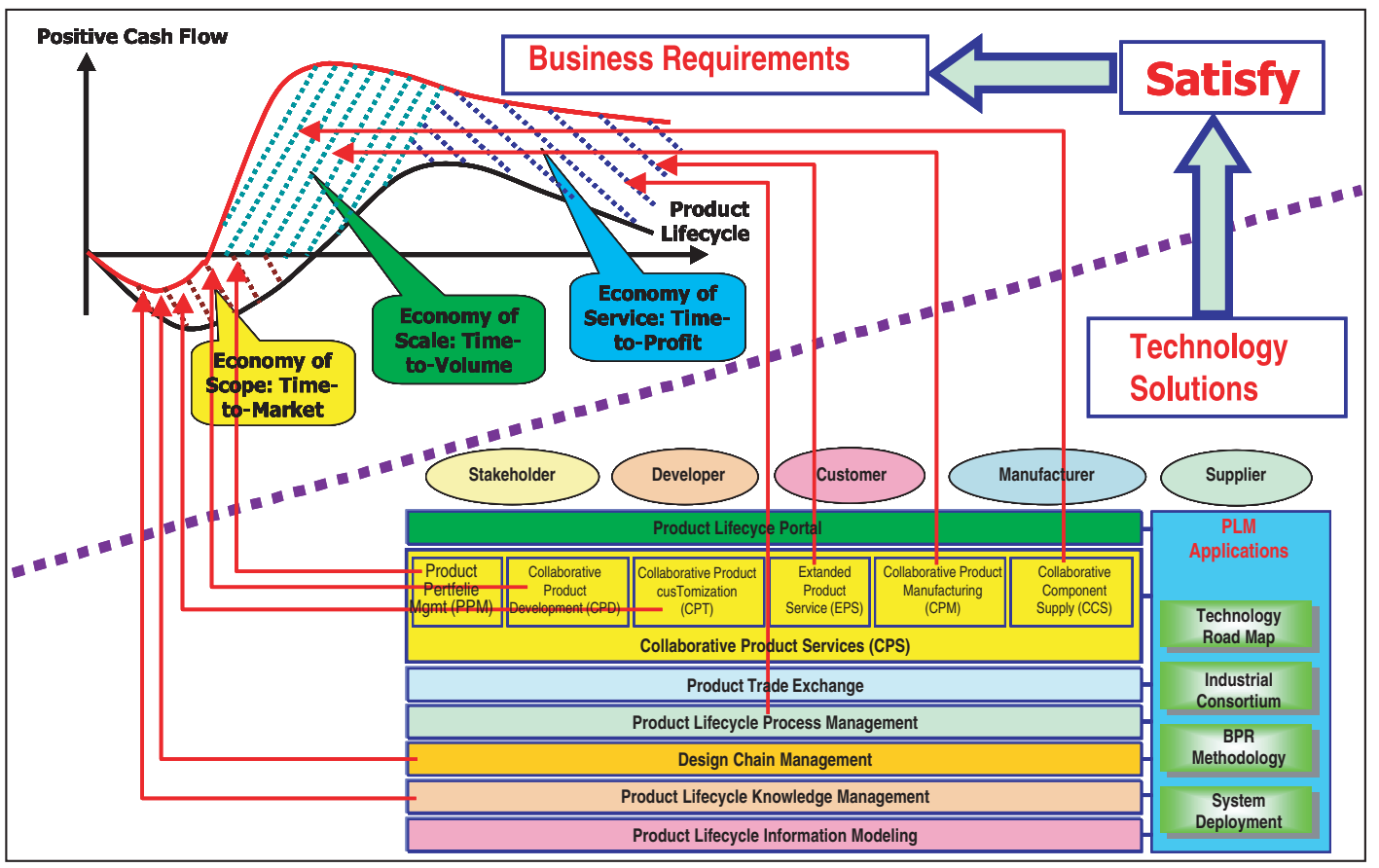

Figure 2. PLM technology solutions address business requirements. 


\section{References}

1. Proud, S. and Wetzer, M. (2003). The Product Lifecycle Management Opportunity. Available at http://www.ascet. com/documents.asp?d_ID $=2015$.

2. Miller, E. (2005). Miller's 2005 State of PLM Address. Available at http://www.cimdata.com/publications/ PLM_State_of_Industry_October_2005.pdf.

3. PLM Webcast (2004). New Product Development and Introduction: Achieve Higher Profit Faster. Available at http://www.amrresearch.com/events/presentations.asp?id $=79$.

4. Brown, J. (2002). The PLM Program, an Incremental Approach to the Strategic Value of PLM, http://www. technologyevaluation.com.

5. Szykman, S., Sriram, R.D. and Regli, W.C. (2001). The Role of Knowledge in Next-Generation Product Development Systems, Transactions of the ASME, Journal of Computing and Information Science in Engineering, 1: 3-11.

6. Zhang, H.C. and Alting, L. (1994). Computerized Manufacturing Process Planning Systems, New York: Chapman \& Hall.

7. Anthony, L., Regli, W.C., John, J.E. and Lombeyda, S.V. (2001). An Approach to Capturing Structure, Behavior, and Function of Artifacts in Computer-Aided Design, Transactions of the ASME, Journal of Computing and Information Science in Engineering, 1: 186-192.

8. Ciocoiu, M., Nau, D.S. and Gruninger, M. (2001). Ontologies for Integrating Engineering Applications, Transactions of the ASME, Journal of Computing and Information Science in Engineering, 1: 12-22.

9. Svensson, D. and Malmqvist, J. (2002). Strategies for Product Structure Management of Manufacturing Firms, Transactions of the ASME, Journal of Computing and Information Science in Engineering, 2: 50-58.

10. Tokyo (2003). Product Life Cycle Modeling Group, University of Tokyo, http://www.cim.pe.u-tokyo.ac.jp/lc/ index.html.

11. Stanford (2003). Center for Design Research, Stanford University, http://www-cdr.stanford.edu/.

12. MIT (2003). Center for Innovation for Product Development, Massachusetts Institute of Technology, http://cipd.mit.edu/.

13. Berkeley (2003). CyberCut Project, University of California at Berkeley, http://cybercut.berkeley.edu/.

14. Georgia (2003). Systems Realization Laboratory, Georgia Insti-tute of Technology, http://srl.marc.gatech.edu/.

15. FIPER (2003). Federated Intelligent Product EnviRonment, http://www.engineous.com/product_ FIPER.htm.

16. IViP Project (2004). Integrated Virtual Product Creation. Available at http://www.ivip.de/.

17. PLM Products and Services (2005). Available at http:// www.ugs.com.cn/solutions/index.aspx.

18. Completed Product Development System (2005). Available at http://www.ptc.com.

19. IBM PLM (2005) Available at http://www-03.ibm.com/ solutions/plm/index.jsp.

20. Changing the Way the World Brings Products to Market (2005). Available at http://www.matrixone.com/.

21. Managing the product record, (2005) Available at http:// www.agile.com/plm/index.asp.
22. Workflow Handbook (2004). Available at http:// www.wfmc.org/information/handbook04.htm.

23. CSC White Paper (2002). The Emergence of Business Process Management. Available at http://lef.csc.com/ process/bpmreport/Default.asp.

24. Ullman, D.G. (1997). The Mechanical Design Process, New York: McGraw-Hill.

\section{G. Ming}

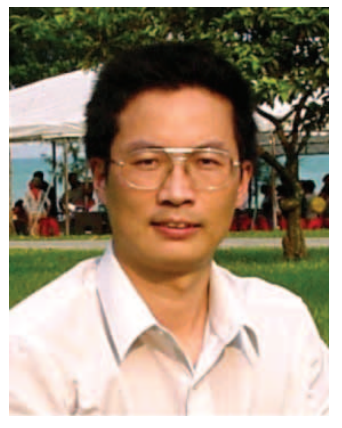

Dr X. G. Ming gained his Bachelor's degree (1988) from the Huazhong University of Science and Technology and his Master's and PhD degree's (1995) from Shanghai Jiao Tong University. He is currently working at the Institute of Computer Integrated Manufacturing, School of Mechanical and Power Engineering, Shanghai Jiao Tong University. He has the experience in research, development, and application of integrated process planning for concurrent engineering, innovation-centric product design process modeling and management, product design knowledge capturing and reuse, enterprise information modeling and integration, enterprise resource planning. His current research interests include Product Lifecycle Management, Collaborative Manufacturing Ecosystem and Enterprise Knowledge Management. He has published in more than 35 prestigious international journals and presented conference papers. He has actively served as a member of the international program committee and chaired sessions and discussion panels at a few international conferences. $\mathrm{He}$ is a senior member of Society of Manufacturing Engineer (SME) since 1999, and a member of Institute of Electrical and Electronics Engineer (IEEE) since 2000.

\section{J. Q. Yan}

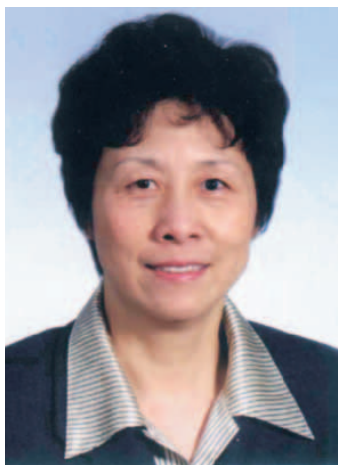

J. Q. Yan received Bachelor's, and Master's degrees from Shanghai Jiao Tong University in 1967, 1981, and a $\mathrm{PhD}$ from Denmark Technical University in 1986 respectively. She is currently a Professor and Dean of the school of mechanical and power engineering of Shanghai Jiao Tong University, Deputy Executive Director of Shanghai Advanced Manufacturing 
Engineering Center, member of Shanghai Information Industry Expert Group. She has been the key expert for 1st and 2nd National 863 Plan CIMS theme, and the founder of Institute of Computer Integrated Manufacturing. She has the experience of research, development, and application of Product Modeling in CIM System, Architecture and Tools for Integrative CAPP System, Integrated CAD/CAPP/CAM System based on Product Modeling, Methodology and Technology for Virtual Manufacturing. Her current research interests include Virtual Manufacturing (VM), Enterprise Information Integration and so on. She has published in more than 50 prestigious international journals and presented conference papers. She was conferred awards of Scientific Researcher, Young Researcher in University of China, Woman Representative, Distinguished Researcher in 863 Plan and so on in the past decade. http://me.sjtu.edu.cn/ szdw/junqi_yan.htm.

\section{W. F. Lu}

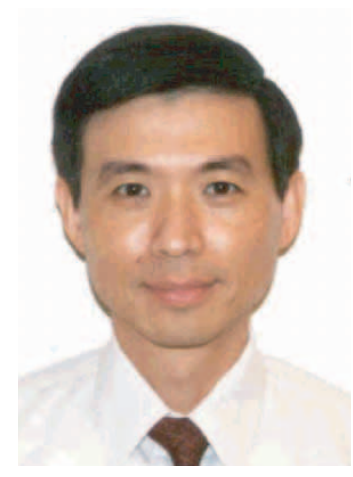

W. F. $\mathrm{Lu} \mathrm{PhD,} \mathrm{is} \mathrm{currently}$ an Associate Professor of the Mechanical Engineering Department, National University of Singapore (NUS). After receiving his $\mathrm{PhD}$, he started as the Assistant Professor at the University of Missouri-Rolla in 1989 and later was promoted to Associate Professor with tenure in 1996. He has led and has been involved in many projects, in the areas of product design and analysis, AI in design and manufacturing, CAD/CAM integration, and intelligent control of manufacturing sponsored by National Science Foundation and companies in USA. He was with Singapore Institute of Manufacturing Technology (SIMTech) since 1999 as a senior scientist as well as program head for six years before joining NUS. He has been involved in several projects, including Integrated PROcess planning for Simultaneous Engineering (INPROSE), Enterprise Process Centric Information Technology (EPC-IT) system, knowledge discovery, product innovation, and product lifecycle management. $\mathrm{He}$ is the recipient of 1997 Society of Automotive Engineers (USA) Ralph R. Teetor Educational Award and 1998 Society of Automotive Engineers Faculty Advisor Award.

\section{Z. Ma}

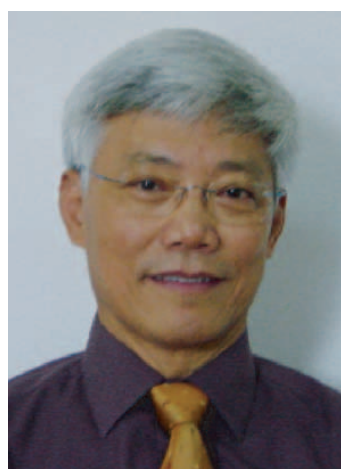

D. Z. Ma received his Bachelor's degree and $\mathrm{PhD}$ from Shanghai Jiao Tong University in 1964 and Germany Darmstad Technological University in 1986 respectively. $\mathrm{He}$ is currently the Professor and Director of the Institute of Computer Integrated Manufacturing, School of Mechanical and Power Engineering of Shanghai Jiao Tong University, Leader of Shanghai CIMS Application Expert Group. He has the experience in research, development, and application of different technologies in CIM System funded by National Natural Foundation, National 863 Plan, Shanghai Science and Technology Bureau, and so on. His current research interests include integrative manufacturing - the application of information technology in product design, manufacturing and enterprise management, virtual manufacturing, reverse engineering, and rapid prototyping. He has published papers in more than 40 prestigious international journals and presented conference papers. He was conferred awards of Scientific Researcher, Distinguished Researcher in 863 Plan and so on in the past decade. http://me.sjtu.edu.cn/szdw/ dengzhe_ma.htm. 